\title{
Clinical study of 200 patients with recurrent aphthous stomatitis
}

\author{
Alberto Rodríguez-Archilla ${ }^{1}$ and Tarik Raissouni \\ ${ }^{1}$ Universidad de Granada, Faculty of Dentistry, Oral Medicine Unit, Granada, Spain; ${ }^{2}$ Centro Odontológico Mfedal Afailal Bab Okla, Tétouan, Morocco
}

\begin{abstract}
Introduction: Recurrent aphthous stomatitis (RAS) affects approximately $20 \%$ of the general population. Its etiology is still unknown. Objective: To analyze this entity's clinical features. Method: Data such as age, gender, family history of RAS, age at first episode onset, prodromal symptoms, number, size, morphology and localization of lesions, RAS clinical form, annual rate of recurrence, predisposing factors, symptoms and time for symptoms and lesions disappearance were assessed in 200 patients with RAS. Results: Patients had RAS minor forms. Main clinical characteristics were family history of RAS (89\%), first episode at $\geq 10$ years of age (69\%), prodromal symptoms (66\%), one lesion per episode (63\%), < $0.5 \mathrm{~cm}$ lesions (64\%), rounded morphology (55\%), localization at the tongue (27\%), 3 recurrent episodes per year (36\%), stress as predisposing factor (34\%), symptom disappearance in 2 days (54\%) and healing of lesions in 8 days (40\%). Conclusion: Even when RAS is a common disorder of the oral mucosa, there is no curative treatment available. Therapeutic measures seek to reduce the pain and size of lesions, accelerate the time of recovery and decrease the rate of relapses.
\end{abstract}

KEY WORDS: Mouth diseases. Recurrent aphthous stomatitis. Oral mucosa.

\section{Introduction}

Recurrent aphthous stomatitis (RAS) remains oral mucosa most common ulcerative disease. ${ }^{1}$ RAS is characterized by the appearance of one or several painful ulcers (aphthae), which initially are necrotic, covered by a white or greyish pseudomembrane and surrounded by a well-defined erythematous halo. The lesions usually affect non-keratinized oral mucosa, can persist for days or weeks and subsequently recur after highly variable periods. ${ }^{2,3}$

RAS affects approximately $20 \%$ of the general population, although some studies indicate from 5 to $60 \%$, depending on ethnic and socioeconomic group. ${ }^{3,4}$ These lesions are common in patients between 10 and 40 years of age, and have a predilection for the female gender and for high socioeconomic status individuals. ${ }^{5,6}$

RAS is considered to be a multifactorial process where different triggering factors and an underlying immune alteration are combined. ${ }^{7}$ Currently, RAS etiopathogenesis is not fully understood, although its onset has been associated with diverse factors, with genetic factors such as a family history related to this condition standing out. ${ }^{8}$ Other related factors are food allergy, local trauma, hormonal changes (such as those of the menstrual cycle), stress and anxiety, nutritional deficits, infectious agents and different systemic diseases. ${ }^{4,6,9,10}$ Aphthae are less common in smokers, which suggests that tobacco plays a possible protective role. ${ }^{11}$

Immune response in RAS is characterized by keratinocyte antigenic stimulation, which favors $T$ cell12,13 activation and immunoglobulins, ${ }^{14}$ circulating immunocomplexes, ${ }^{15}$ cytokines and adhesion molecules ${ }^{16-18}$ participation. This results in lymphocyte accumulation and in the development of a cytotoxic response that induces the appearance of ulcers in the oral mucosa. ${ }^{6,9,19}$

According to the lesions' size, three clinical forms of RAS have been described: minor aphthae, major aphthae and herpetiform aphthae. ${ }^{4,20}$
Correspondence:

Alberto Rodríguez-Archilla

E-mail: alberodr@ugr.es
Date of reception: 03-04-2016

Date of acceptance: 19-04-2016

DOI://dx.doi.org/10.24875/GMM.M18000125
Gac Med Mex. 2018;154:122-128

Contents available at PubMed www.gacetamedicademexico.com 
Minor aphthae are the most common (> $85 \%$ of cases), and are characterized by superficial lesions of less than $1 \mathrm{~cm}$ in diameter, which normally appear in non-keratinized oral mucosa and heal in one to two weeks without leaving a scar. ${ }^{4,20}$

Major aphthae are less common (10\% of cases) and produce lesions $>1 \mathrm{~cm}$ in diameter, deeper and very painful. They can appear in non-keratinized and keratinized mucosa. They require more than 2 weeks to heal, and often do it leaving a scar.

Herpetiform aphthae (5\% of cases) are characterized by episodes of multiple, small (2 to $3 \mathrm{~mm}$ ), superficial lesions, grouped in the form of clusters and distributed throughout non-keratinized mucosa. The lesions tend to coalesce and to form larger irregular ulcers. They usually heal in 7 to 10 days without leaving a scar. Clinically, they can be mixed up with recurrent intraoral herpes. ${ }^{4,20}$

RAS diagnosis is based on patient history and clinical findings, but there are no specific diagnostic tests. Its association with some systemic diseases such as Behçet's disease, cyclic neutropenia, celiac disease, periodic fever, adenitis, pharyngitis and aphthae (PFA$\mathrm{PA})$ syndrome, oral and genital ulcers with inflamed cartilage (MAGIC) syndrome, Sweet's syndrome, Reiter's disease or some immunodeficiencies should be taken into account. ${ }^{21-23}$

RAS is of unknown origin, and specific treatment is therefore not available; therapeutic measures are basically aimed at minimizing symptoms and preventing recurrences. The choice of topical or systemic treatment depends on symptom severity, lesion size and number and on the frequency of recurrent episodes. ${ }^{4}$

The purpose of this study was to analyze RAS clinical characteristics in a series of patients who attended a dentistry practice to receive treatment.

\section{Method}

Two hundred patients who attended a dental practice in Tétouan, Morocco, to receive dental care between January 2013 and January 2015 were included. The detection of lesions was a casual finding during oral examination. All subjects were provided the necessary information about the purposes of this work with the purpose to obtain their consent. The information was incorporated to a clinical record especially designed for this purpose. The study protocol was approved by the Human Research Ethics Committee of the Faculty of Dentistry, University of Granada (registry FOD-UGR-054/2012).
Patients who refused to participate in the investigation, who didn't sign the informed consent, with the smoking habit, who consumed alcohol regularly, and those with systemic diseases related to the appearance of mouth ulcers were excluded. All patients were diagnosed on the first day of lesions' appearance.

Each patient was applied a questionnaire that included age, gender, family history of RAS, age at first episode appearance, prodromal symptoms, number, size, morphology and site of lesions at each episode, RAS clinical presentation, recurrence rate (number of episodes/year), predisposing factors, symptoms of the process and time to symptoms and lesions disappearance.

Descriptive statistics (arithmetical mean, standard deviation and averages) and analytical statistics were used for comparison of variables, by means of parametric (Student's t-test, ANOVA) and non-parametric tests (Mann-Whitney U-test, Kruskal-Wallis test, chisquare test and Fisher's test, as required). Eowest significance level was considered at a $p$-value $<0.05$. Data were processed with the statistical program SPSS Statistics, version 22.0 (IBM Corp., Armonk, NY, USA).

\section{Results}

Of the 200 included patients, 120 were females $(60 \%)$ and 80 were males (40\%), with a mean age of $34.20 \pm 13.77$ years and a range of 10 to 74 years. No statistically significant differences were found between both population groups in terms of age and gender.

Table 1 shows the clinical characteristics of the 200 patients with RAS. The patients referred a previous family history of RAS, had their first episode at $\geq 10$ years of age, had prodromal symptoms, one single lesion per episode, lesions of $<0.5 \mathrm{~cm}$ in diameter, of rounded morphology, and the majority located at the tongue. All subjects had minor aphthae, with a recurrence rate of 3 episodes per year; stress was the most commonly referred predisposing factor. The lesions were painful, and in $20 \%$ of patients there was associated functional impairment coexisting; symptoms disappeared in two days, and most Tesions healed at eight days of their appearance.

When the age was compared with some clinical parameters of the study (Table 2), a mean older age was observed in those patients who had their first RAS episode at $\geq 10$ years of age $(p<0.001)$, with lesions $>0.5 \mathrm{~cm}$ in diameter $(p<0.01)$, of irregular morphology 
Table 1. Main clinical characteristics in 200 individuals with recurrent aphthous stomatitis

\begin{tabular}{|c|c|c|c|c|c|c|}
\hline Parameter & $\mathrm{n}$ & $\%$ & Parameter & $\mathbf{n}$ & & $\%$ \\
\hline \multicolumn{3}{|l|}{ Family history of RAS } & \multicolumn{2}{|l|}{ Recurrence rate/year } & $\stackrel{\infty}{\leftarrow}$ & \\
\hline Yes & 178 & 89 & 1 time & 4 & $\stackrel{ }{N}$ & 2 \\
\hline \multirow[t]{2}{*}{ No } & 22 & 11 & 2 times & 32 & $\frac{1}{a}$ & 16 \\
\hline & & & 3 times & 72 & $\geq 3$ & 36 \\
\hline \multicolumn{3}{|l|}{ First RAS episode } & 4 times & 26 & $\frac{\varsigma}{\sigma}$ & 13 \\
\hline$<10$ years & 62 & 31 & 5 times & 50 & $\frac{E}{5}$ & 25 \\
\hline$\geq 10$ years & 138 & 69 & $\geq 6$ times & 8 & 2 & 4 \\
\hline \multicolumn{3}{|l|}{ Prodromal symptoms } & Continuous & 8 & () & 4 \\
\hline Yes & 132 & 66 & \multicolumn{4}{|l|}{ Predisposing factors } \\
\hline No & 68 & 34 & None & 26 & $\frac{1}{4}$ & 13 \\
\hline \multicolumn{3}{|l|}{ Number of lesions } & Stress & 68 & $\frac{c}{n}$ & 34 \\
\hline 1 & 126 & 63 & Food allergy & 34 & (- & 17 \\
\hline 2 & 56 & 28 & Bowel disorders & 30 & 党. & 15 \\
\hline 3 & 18 & 9 & Local trauma & 28 & (1) & 14 \\
\hline & 18 & & Hormonal changes & 14 & $\subsetneq$ & 7 \\
\hline \multirow{3}{*}{$\begin{array}{l}\text { Lesion diameter } \\
<0.5 \mathrm{~cm} \\
0.5-1 \mathrm{~cm}\end{array}$} & & & Other allergies & 0 & 0 & 0 \\
\hline & 128 & 64 & & & $\frac{\varsigma}{0}$ & \\
\hline & 72 & 36 & Symptoms & 160 & $\bar{n}$ & 80 \\
\hline \multicolumn{3}{|l|}{ Lesion morphology } & Pain + functional impairment & 40 & $\frac{E}{a}$ & 20 \\
\hline Rounded & 110 & 55 & & & $\stackrel{0}{2}$ & \\
\hline Oval-shaped & 64 & 32 & Symptoms disappearance & & $\subsetneq$ & \\
\hline Irregular & 26 & 13 & 1 day after & 76 & \pm & 38 \\
\hline \multirow{2}{*}{\multicolumn{3}{|c|}{ Lesion site }} & 2 days after & 108 & 5 & 54 \\
\hline & & & 3 days after & 16 & $\begin{array}{l}3 \\
3\end{array}$ & 8 \\
\hline Tongue & 54 & 27 & & & 흐 & \\
\hline Floor of mouth & 28 & 14 & Healing of lesions & & 흐 & \\
\hline Upper lip mucosa & 14 & 7 & 6 days after & 36 & $(1)$ & 18 \\
\hline Lower lip mucosa & 16 & 8 & 7 days after & 62 & 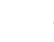 & 31 \\
\hline Buccal mucosa & 10 & 5 & 8 days after & 80 & $\frac{3}{3}$ & 40 \\
\hline Soft palate & 0 & 0 & 9 days after & 0 & 욷 & 0 \\
\hline Hard palate & 0 & 0 & 10 days after & 22 & $\frac{+}{2}$ & 11 \\
\hline Gums & 0 & 0 & $>10$ days after & 0 & o) & 0 \\
\hline Several sites & 78 & 39 & & & $\frac{1}{\infty}$ & \\
\hline \multicolumn{7}{|l|}{ RAS clinical form } \\
\hline Minor & 200 & 100 & & & 号 & \\
\hline Major & 0 & 0 & & & 닫 & \\
\hline Herpetiform & 0 & 0 & & & $\frac{2}{2}$ & \\
\hline
\end{tabular}

$(p<0.01)$, located at the floor of mouth $(p<0.001)$, and with an annual recurrence rate of $\geq 6$ episodes $(p<0.001)$, as well as in those who referred food allergy as a predisposing factor $(\mathrm{p}<0.05)$. For the remaining factors (family history of RAS, prodromal symptoms, number of lesions, symptomatology, disappearance of symptoms or lesions), comparisons with age were not statistically significant.

When the influence of gender on some clinical parameters was analyzed (Table 3), more females than males were found to have experienced their first RAS episode at $<10$ years of age $(p<0.001)$ and to have lesions $<0.5 \mathrm{~cm}$ in diameter $(p<0.05)$. Conversely, more males than females were found to refer stress, bowel disorders or food allergy as predisposing factors $(p<0.01)$. The remaining comparisons were not statistically significant.
A direct relationship was observed between prodromal symptoms experienced by the patients and a higher number of lesions per episode $(p<0.001)$ or with lesions located at lower lip mucosa $(p<0.001)$.

Regarding the comparison between the number of lesions per RAS episode and some clinical parameters (Table 4), a higher mean number of lesions was found in males $(p<0.05)$, in patients who had the first RAS episode at $\geq 10$ years of age $(p<0.001)$, with lesions $<0.5 \mathrm{~cm}$ in diameter $(p<0.05)$ and with continuous annual recurrence rate $(p<0.05)$. For the remaining parameters, the comparisons with the mean number of lesions per episode were not statistically significant.

The relationship between lesion size and some studied clinical parameters is shown in Table 5 . Among the small lesions $(<0.5 \mathrm{~cm}$ in diameter $)$, 
Table 2. Influence of age on clinical parameters in $\mathbf{2 0 0}$ individuals with recurrent aphthous stomatitis

\begin{tabular}{|c|c|c|c|}
\hline Parameter & $\begin{array}{l}\text { Patients } \\
\text { (n) }\end{array}$ & $\begin{array}{c}\text { Age } \\
(\bar{x} \pm S D)\end{array}$ & $p$ \\
\hline \multicolumn{4}{|c|}{ Age at first episode (years) } \\
\hline$<10$ & 62 & $27.65 \pm 9.88$ & $<0.001$ \\
\hline$\geq 10$ & 138 & $37.14 \pm 14.27$ & \\
\hline \multicolumn{4}{|l|}{ Lesion size } \\
\hline Small $(<0.5 \mathrm{~cm})$ & 128 & $32.27 \pm 12.80$ & $<0.01$ \\
\hline Large $(0.5-1 \mathrm{~cm})$ & 72 & $37.64 \pm 14.82$ & \\
\hline \multicolumn{4}{|l|}{ Lesion morphology } \\
\hline Round-oval-shaped & 174 & $32.84 \pm 13.43$ & $<0.01$ \\
\hline Irregular & 26 & $43.31 \pm 12.70$ & \\
\hline \multicolumn{4}{|l|}{ Lesion site } \\
\hline Floor of mouth & 28 & $47.43 \pm 13.97$ & $<0.001$ \\
\hline Rest of sites & 172 & $32.05 \pm 12.51$ & \\
\hline \multicolumn{4}{|l|}{ Annual recurrence rate } \\
\hline 1 time & 4 & $18.50 \pm 8.66$ & $<0.05$ \\
\hline Other & 196 & $34.52 \pm 13.68$ & \\
\hline \multicolumn{4}{|l|}{ Predisposing factors } \\
\hline Food allergy & 34 & $38.65 \pm 15.27$ & $<0.05$ \\
\hline Other factors & 166 & $33.29 \pm 13.31$ & \\
\hline
\end{tabular}

Table 3. Clinical parameters association with gender in 200 individuals with recurrent aphthous stomatitis

\begin{tabular}{|c|c|c|c|c|c|}
\hline \multirow[t]{3}{*}{ Parameter } & \multicolumn{4}{|c|}{ Gender } & \multirow[t]{3}{*}{ p } \\
\hline & \multicolumn{2}{|c|}{ Male } & \multicolumn{2}{|c|}{ Female } & \\
\hline & $\mathrm{n}$ & $\%$ & $\mathbf{n}$ & $\%$ & \\
\hline \multicolumn{6}{|c|}{ Age at first episode (years) } \\
\hline$<10$ & 16 & 20.0 & 46 & 38.3 & $<0.01$ \\
\hline$\geq 10$ & 64 & 80.0 & 74 & 61.7 & \\
\hline \multicolumn{6}{|l|}{ Lesion size (diameter) } \\
\hline Small $(<0.5 \mathrm{~cm})$ & 44 & 55.0 & 84 & 70.0 & $<0.05$ \\
\hline Large $(0.5-1 \mathrm{~cm})$ & 36 & 45.0 & 36 & 30.0 & \\
\hline \multicolumn{6}{|l|}{ Predisposing factors } \\
\hline None & 8 & 10.0 & 18 & 15.0 & $<0.01$ \\
\hline Stress & 30 & 37.5 & 38 & 31.7 & \\
\hline Bowel disorders & 16 & 20.0 & 14 & 11.6 & \\
\hline Local trauma & 8 & 10.0 & 20 & 16.7 & \\
\hline Food allergy & 18 & 22.5 & 16 & 13.3 & \\
\hline Hormonal changes & 0 & 0.0 & 14 & 11.7 & \\
\hline
\end{tabular}

rounded lesions $(p<0.001)$, located at the tongue $(p<0.001)$ and that healed 6 days after their appearance $(p<0.01)$ stood out. In contrast, among the large lesions ( 0.5 to $1 \mathrm{~cm}$ in diameter), oval-shaped lesions $(p<0.001)$, located on the floor of mouth $(p<0.001)$ and those that healed 10 days after their appearance $(p<0.01)$ stood out.

When the influence of predisposing factors on the time to symptoms or lesions disappearance was analyzed, symptoms were observed to have
Table 4. Relationship between mean number of lesions and some clinical parameters in $\mathbf{2 0 0}$ individuals with recurrent aphthous stomatitis

\begin{tabular}{|c|c|c|c|c|}
\hline Parameter & $\mathbf{n}$ & $\begin{array}{c}\text { Number of lesions } \\
\text { (mean) }\end{array}$ & s- & $p$ \\
\hline \multicolumn{5}{|l|}{ Gender } \\
\hline Male & 80 & $1.58 \pm 0.70$ & $\frac{\mathrm{c}}{\mathrm{\sigma}}$ & $<0.05$ \\
\hline Female & 120 & $1.38 \pm 0.61$ & $\frac{\text { है }}{1}$ & \\
\hline \multicolumn{5}{|c|}{ Age at first episode (years) } \\
\hline$<10$ & 62 & $1.26 \pm 0.51$ & & $<0.01$ \\
\hline$\geq 10$ years & 138 & $1.55 \pm 0.69$ & & \\
\hline \multicolumn{3}{|l|}{ Lesion size } & $\frac{0}{n}$ & \\
\hline Small $(<0.5 \mathrm{~cm})$ & 128 & $1.53 \pm 0.68$ & 此 & $<0.05$ \\
\hline Large $(0.5-1 \mathrm{~cm})$ & 72 & $1.33 \pm 0.58$ & $\frac{0}{3}$ & \\
\hline \multicolumn{3}{|l|}{ Recurrence rate } & $\stackrel{0}{\frac{1}{c}}$ & \\
\hline Continuous & 8 & $2.00 \pm 1.07$ & + & $<0.05$ \\
\hline Other rates & 192 & $1.44 \pm 0.63$ & O & \\
\hline
\end{tabular}

disappeared at 3 days in half of the patients who referred food allergy as a predisposing factor, with statistically significant association being found $(p<0.01)$. The lesions healed after 10 days in $72.5 \%$ of patients in whom stress was the predisposing factor, with a statistically significant relationship $(p<0.001)$.

\section{Discussion}

Even though RAS is the most common ulcerative disease of the oral mucosa, its etiology is not entirely understood and there is no fully curative treatment. ${ }^{1}$

The population with RAS of the present study had a mean age of $34.20 \pm 13.77$ years, with a range between 10 and 74 years, which is consistent with the information obtained by Chattopadhyay et al. ${ }^{24}$ in a large study in a large study in 20,050 North American adults with RAS, in whom mean age was $36.10 \pm$ 1.92 years. In Jordan, patients included in the work by Safadi ${ }^{25}$ had a mean age of 37.5 years, with a range from 13 to 68 . In turn, Brailo et al. ${ }^{26}$ recorded a mean age of 38.8 years, ranging from 5 to 73 , in 68 Croatian patients. Oh et al. ${ }^{27}$ found a mean age of 40.75 years in 1643 Chinese patients. Other studies have recorded mean ages of $41.77 \pm 20.71$ years, ranging from 21 to 65 years; ${ }^{28} 43.08 \pm 8.37$ years, ranging from 21 to $65 ; 2942.80 \pm 14.30$ years, ranging from 17 to $79 .{ }^{30}$ Although RAS is more common in young than in adult individuals, ${ }^{4,24}$ in this study it was the opposite: $27 \%$ of patients were within the range of 20 to 30 years, while $17 \%$ were within the range of 10 to 20 years. 


\begin{tabular}{|c|c|c|c|c|c|c|}
\hline \multirow[t]{3}{*}{ Parámetro } & \multicolumn{4}{|c|}{ Lesion size } & \multirow{3}{*}{$\begin{array}{l}\infty \\
\frac{\infty}{6} \\
\frac{1}{4}\end{array}$} & \multirow[t]{3}{*}{$p$} \\
\hline & \multicolumn{2}{|c|}{ Small $(<0.5 \mathrm{~cm})$} & \multicolumn{2}{|c|}{ Large $(0.5-1 \mathrm{~cm})$} & & \\
\hline & $\mathrm{n}$ & $\%$ & $\mathrm{n}$ & $\%$ & & \\
\hline \multicolumn{7}{|l|}{ Lesion morphology } \\
\hline Rounded & 84 & 65.6 & 26 & 36.1 & $<$ & 0.001 \\
\hline Oval-shaped & 34 & 26.6 & 30 & 41.7 & $\frac{5}{1}$ & \\
\hline Irregular & 10 & 7.8 & 16 & 22.2 & (1) & \\
\hline \multicolumn{7}{|l|}{ Lesion site } \\
\hline Tongue & 40 & 31.3 & 14 & 19.4 & & 0.001 \\
\hline Floor of mouth & 4 & 3.1 & 24 & 33.3 & $\frac{c}{n}$ & \\
\hline Upper lip mucosa & 12 & 9.4 & 2 & 2.8 & 臬 & \\
\hline Lower lip mucosa & 10 & 7.8 & 6 & 8.3 & 굴 & \\
\hline Buccal mucosa & 6 & 4.7 & 4 & 5.6 & 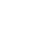 & \\
\hline Several sites & 56 & 43.8 & 22 & 30.6 & $\subsetneq$ & \\
\hline \multicolumn{7}{|c|}{ Lesion healing (days after) } \\
\hline 6 & 30 & 83.3 & 6 & 8.3 & & 0.01 \\
\hline 7 & 36 & 58.1 & 26 & 41.9 & $\cong$ & \\
\hline 8 & 54 & 67.5 & 26 & 32.5 & ह & \\
\hline 10 & 8 & 36.4 & 14 & 63.6 & $\frac{1}{\partial}$ & \\
\hline
\end{tabular}

Most authors $3,7,25,27-29,31$ agree on pointing out that RAS affects females more often; however, in some studies, ${ }^{2,32}$ the prevalence was the same for both genders, as in the study by Majorana et $a .^{33}$ in Italian children $<12$ years, with a slight predominance of the male gender being observed. Consistently with findings in our work, RAS was more common in females (60\%).

A conditioning factor for the development of RAS is the existence of a family history thereof. ${ }^{25,31,34}$ In fact, patients with a family history of the condition had $90 \%$ probabilities for developing RAS, in contrast with $20 \%$ of patients without a family history. ${ }^{4}$ In the presented research, $89 \%$ of patients referred a family history of RAS.

Some investigations ${ }^{3,7,35}$ place the first RAS episode at the second decade of life, in coincidence with the onset of puberty, which is consistent with the obtained results: $69 \%$ of patients had their first episode at between 10 and 20 years of age versus $31 \%$ in whom the first episode occurred before 10 years of age.

As for the number of lesions, different authors ${ }^{1,2,36-38}$ indicate that RAS episodes occur with less than 3 lesions in most occasions. In this work, $63 \%$ of patients had episodes with one single lesion. Safadi, ${ }^{25}$ in his study on 561 patients, observed $49.2 \%$ of patients with one single lesion per episode. The number of lesions per episode was conditioned by gender, age at onset of first episode, lesion size and annual recurrence rate.

Nearly all investigations coincide in associating lesion size with RAS clinical form, ${ }^{1,2,4,7,19,20,35}$ differentiating between minor (diameter $<1 \mathrm{~cm}$ ), major (diameter $>1 \mathrm{~cm}$ ) and herpetiform $(2$ to $3 \mathrm{~mm}$ ) forms. In this study, all RAS lesions were minor, which in general terms are the most common ( $85 \%$ of cases). ${ }^{4,20}$

With regard to lesion form, most authors $2,3,7,19,32,36,37,39$ distinguish between irregular and regular (oval or round-shaped) lesions, with the latter being the most common and associated with RAS minor forms. The results of the present work ( $87 \%$ of lesions with regular and $13 \%$ with irregular morphology) are consistent with those published by other investigators. The records carried out by Safadi ${ }^{25}$ indicate $34.3 \%$ of irregular and $65.7 \%$ of regular lesions, which disagrees with our findings, although more than $15 \%$ of his patients had RAS major forms.

Numerous studies ${ }^{1-7,9,19,32,35}$ concur in indicating a predilection of RAS lesions to be located on areas of non-keratinized oral mucosa. Similarly, the most common lesion site in this study was the tongue, with $27 \%$ of cases, followed by internal lip mucosa (15\%), floor of mouth (14\%) and buccal mucosa (5\%). No case was located on the soft palate or keratinized oral mucosa (hard palate, gums). The tongue is also referred to as the most common site of RAS lesions in the works by Salafij ${ }^{25}$ in Jordan, Oh et al. ${ }^{27}$ in China or 
López-Jornet et al. ${ }^{28}$ in Spain. In contrast, others ${ }^{1,2,31,40}$ refer to internal lip mucosa as the most common lesion site, before the tongue.

In the present work, annual recurrence rate was 3 episodes (36\%), followed by 5 episodes (25\%), 2 episodes (16\%) and only $4 \%$ of patients had aphthae continuously. In concordance with these results, Axell and Henricsson, ${ }^{40}$ in a study about 3500 patients, only found $1 \%$ of continuous recurrence, $15 \%$ of frequent occurrence and $84 \%$ of intermittent clinical signs and symptoms, i.e., patients who experienced less than 6 episodes per year. Contrariwise, Bagán et al., ${ }^{38}$ when analyzing a series of 93 patients, observed that $53.8 \%$ had an annual recurrence rate of 5 to 8 episodes, which is higher than that found in our study. The apparent discrepancies between different authors regarding annual RAS recurrence rate could be attributed to differences in sample size and to the establishment of different recurrent intervals in the studies' methodological design.

Different RAS-associated predisposing factors have been analyzed. In the present study, the 3 most important were stress (34\%), food allergy (17\%) and bowel disorders $(15 \%)$. Stress as a relevant predisposing factor for RAS has been widely suggested in investigations that consider oral mucosa as a target organ in certain emotional disorders. . $3,19,25,30,32,38,41$

The disparity of results around this factor probably lies in the studied sample sizes, type of population and in differences in the investigations' methodological design.

Food allergy as a RAS precipitating factor has also been mentioned. ${ }^{25,42,43}$ There are analyses where it even is the most important predisposing factor: 50 or $75 \%$ of cases. ${ }^{41,43}$ Given the small sample size of those investigations, the results should be regarded as being poorly representative. Furthermore, other particular factors that act with unknown mechanisms should be considered in each patient. Larger studies that delve into this issue and enable discrepancies to be clarified are required.

Bowel disorders, either due to nutritional deficits or gastrointestinal pathology, have also been referred to as triggering causes in different works. ${ }^{1,25,28,44}$

Hormonal changes were the least common predisposing factor $(7 \%)$, which is consistent with reports by Axéll et al. ${ }^{40}(8 \%)$ and Lotufo et al. ${ }^{41}(2.5 \%)$. In a systematic review carried out by McCartan and Sulli$v^{2}{ }^{45}$, no relationship was found between RAS onset and menstrual cycle, pregnancy, menopause or hormone replacement therapy; conversely, some authors $3,7,27,39$ have given much higher relevance to this factor. The differences in this issue could be due to different sample sizes, differences in gender distribution and research approaches.

In this study in patients with RAS minor forms, the majority had a family history of RAS, single-lesion episodes, regular morphology (oval-shaped or rounded) lesions, located mainly on the tongue or internal labial mucosa and with an annual recurrence rate of 3 episodes. The most commonly related triggering factor was stress, time to symptoms disappearance was 2 days and time to remission was 8 days after the bout.

Even though RAS is one of the most common disorders of the oral mucosa and its clinical characteristics are well defined, its specific etiology and pathogenesis remain unclear and, therefore, there is no curative treatment available. Therapeutic measures are aimed at reducing pain, accelerating the healing period and decreasing the frequency of relapse, and new works delving into the study of the etiopathogenic mechanisms of this condition and its triggering factors are therefore required, in order to find an entirely effective treatment.

\section{References}

1. Porter SR, Scully C, Pedersen A. Recurrent aphthous stomatitis. Crit Rev Oral Biol Med. 1998;9(3):306-21.

2. Ship JA, Chavez EM, Doerr PA, Henson BS, Sarmadi M. Recurrent aphthous stomatitis. Quintessence Int. 2000;31(2):95-112.

3. Jurge S, Kuffer R, Scully C, Porter SR. Mucosal disease series. Number VI. Recurrent aphthous stomatitis. Oral Dis. 2006;12(1):1-21.

4. Akintoye SO, Greenberg MS. Recurrent aphthous stomatitis. Dent Clin North Am. 2014;58(2):281-297.

5. Baccaglini L, Lalla RV, Bruce AJ, Sartori-Valinotti JC, Latortue MC, Carrozzo M, et al. Urban legends: recurrent aphthous stomatitis. Oral Dis. 2011:17(8):755-770.

6. Chavan M, Jain H, Diwan N, Khedkar S, Shete A, Durkar S. Recurrent aphthous stomatitis: a review. J Oral Pathol Med. 2012;41(8):577-583.

7. Porter SR, Hegarty A, Kaliakatsou F, Hodgson TA, Scully C. Recurrent aphthous stomatitis. Clin Dermatol. 2000;18(5):569-578.

8. Albanidou-Farmaki E, Deligiannidis A, Markopoulos AK, Katsares V, Farmakis K, Parapanissiou E. HLA haplotypes in recurrent aphthous stomatitis: a mode of inheritance? Int J Immunogenet. 2008;35(6):427-432.

9. Preeti L, Magesh KT, Rajkumar K, Karthik R. Recurrent aphthous stomatitis. J Oral Maxillofac Pathol. 2011;15(3):252-256.

10. Huling LB, Baccaglini L, Choquette L, Feinn RS, Lalla RV. Effect of stressful life events on the onset and duration of recurrent aphthous stomatitis. J Oral Pathol Med. 2012;41(2):149-152.

11. McRobbie $H$, Hajek $P$, Gillison $F$. The relationship between smoking cessation and mouth ulcers. Nicotine Tob Res. 2004;6(4):655-659.

12. Landesberg $R$, Fallon $M$, Insel $R$. Alterations of $T$ helper/inducer and $T$ suppressor/inducer cells in patients with recurrent aphthous ulcers. Oral Surg Oral Med Oral Pathol. 1990;69(2):205-208.

13. Bachtiar EW, Cornain S, Siregar B, Raharjo TW. Decreased CD4+/CD8+ ratio in major type of recurrent aphthous ulcers: comparing major to minor types of ulcers. Asian Pac J Allergy Immunol. 1998; 16(2-3):75-79.

14. Scully C, Yap PL, Boyle P. IgE and IgD concentrations in patients with recurrent aphthous stomatitis. Arch Dermatol. 1983;119(1):31-34.

15. Rodríguez-Archilla A, Urquía M, Gómez-Moreno G, Ceballos A. Anti-DNA antibodies and circulating immune complexes (C1q-IgG) in recurrent aphthous stomatitis. Bull Group Int Rech Sci Stomatol Odontol. 1994;37(1-2):31-35.

16. Yamamoto T, Yoneda K, Ueta E, Osaki T. Serum cytokines, interleukin-2 receptor, and soluble intercellular adhesion molecule-1 in oral disorders. Oral Surg Oral Med Oral Pathol. 1994;78(6):727-35. 
17. Healy CM, Enobakhare B, Haskard DO, Thornhill MH. Raised levels of circulating VCAM-1 and circulating E-selectin in patients with recurrent oral ulceration. J Oral Pathol Med. 1997;26(1):23-28.

18. Healy $\mathrm{CM}$, Thornhill $\mathrm{MH}$. Induction of adhesion molecule expression on blood vessels and keratinocytes in recurrent oral ulceration. J Oral Patho Med. 1999;28(1):5-11.

19. Scully C, Porter S. Oral mucosal disease: recurrent aphthous stomatitis. Br J Oral Maxillofac Surg. 2008;46(3):198-206.

20. Scully C. Clinical practice. Aphthous ulceration. N Engl J Med 2006;355(2):165-172.

21. Taylor J, Glenny AM, Walsh T, Brocklehurst P, Riley P, Gorodkin R, et al Interventions for the management of oral ulcers in Behçet's disease. Cochrane Database Syst Rev. 2014;(9):CD011018.

22. Maloney WJ, Raymond G, Hershkowitz D, Rochlen G. Oral and denta manifestations of celiac disease. N Y State Dent J. 2014;80(4):45-48.

23. Burton MJ, Pollard AJ, Ramsden JD, Chong LY, Venekamp RP. Tonsillectomy for periodic fever, aphthous stomatitis, pharyngitis and cervical adenitis syndrome (PFAPA). Cochrane Database Syst Rev. 2014;(9): CD008669.

24. Chattopadhyay A, Chatterjee S. Risk indicators for recurrent aphthous ulcers among adults in the US. Community Dent Oral Epidemiol. 2007;35(2):152-159.

25. Safadi RA. Prevalence of recurrent aphthous ulceration in Jordanian dental patients. BMC Oral Health. 2009;9:31.

26. Brailo V, Boras VV, Cekić-Arambasin A. Rekurentne aftozne ulceracije: Analiza predisponirajucih cimbenika u 68 bolesnika. Liječ Vjesn. 2007;129:4-7.

27. Oh SH, Han EC, Lee JH, Bang D. Comparison of the clinical features of recurrent aphthous stomatitis and Behçet's disease. Clin Exp Dermatol. 2009;34(6):e208-e212.

28. López-Jornet $\mathrm{P}$, Camacho-Alonso F, Martos N. Hematological study of patients with aphthous stomatitis. Int J Dermatol. 2014:53(2):159-163.

29. Gavic L, Cigic L, Biocina-Lukenda D, Gruden V, Gruden Pokupec JS The role of anxiety, depression, and psychological stress on the clinical status of recurrent aphthous stomatitis and oral lichen planus. J Oral Pathol Med. 2014;43(6):410-417.

30. Bratel J, Hakeberg M. Anamnestic findings from patients with recurrent aphthous stomatitis. Swed Dent J. 2014;38(3):143-149.
31. McCullough MJ, Abdel-Hafeth S, Scully C. Recurrent aphthous stomatitis revisited; clinical features, associations, and new association with infant feeding practices? J Oral Pathol Med. 2007;36(10):615-620.

32. Casiglia JM. Recurrent aphthous stomatitis: etiology, diagnosis and treatment. Gen Dent. 2002;50(2):157-166.

33. Majorana A, Bardellini E, Flocchini P, Amadori F, Conti G, Campus G. Oral mucosal lesions in children from 0 to 12 years old: ten years' experience. Oral Surg Oral Med Oral Pathol Oral Radiol Endod. 2010;110(1):e13-e18.

34. Slebioda Z, Szponar E, Kowalska A. Etiopathogenesis of recurrent aphthous stomatitis and the role of immunologic aspects: literature review. Arch Immunol Ther Exp (Warsz). 2014;62(3):205-215.

35. Murray LN, Amedee RG. Recurrent aphthous stomatitis. J La State Med Soc. 2000;152(1):10-14.

36. Piantanida EW, Samlaska CP. Recurrent aphthous stomatitis. Oral Surg Oral Med Oral Pathol Oral Radiol Endod. 1996;82(5):472.

37. Rees TD, Binnie WH. Recurrent aphthous stomatitis. Dermatol Clin. 1996;14(2):243-256.

38. Bagán JV, Sanchis JM, Milián MA, Peñarrocha M, Silvestre FJ. Recurrent aphthous stomatitis. A study of the clinical characteristics of tesions in 93 cases. J Oral Pathol Med. 1991;20(8):395-397.

39. Zain RB. Oral recurrent aphthous ulcers/stomatitis: prevalence in Malaysia and an epidemiological update. J Oral Sci. 2000;42(1):15-19.

40. Axéll T, Henricsson V. The occurrence of recurrent aphthous ulcers in an adult Swedish population. Acta Odontol Scand. 1985;43(2):121-125.

41. Lotufo MA, Lemos CA, Shimizu MT, Cabral R, Birman EG. Clinical evaluation of the topical use of propolis in recurrent minor aphthous ulceration. Cienc Odontol Bras. 2005;8(3):6-9.

42. Ogura M, Yamamoto T, Morita M, Watanabe T. A case-control study on food intake of patients with recurrent aphthous stomatitis. Oral Surg Oral Med Oral Pathol Oral Radiol Endod. 2001;91(1):45-49.

43. Nolan A, Lamey PJ, Milligan KA, Forsyth A. Recurrent aphthous ulceration and food sensitivity. J Oral Pathol Med. 1991;20(10):473-475.

44. Koybasi S, Parlak AH, Serin E, Yilmaz F, Serin D. Recurrent aphthous stomatitis: investigation of possible etiologic factors. Am J Otolaryngol. 2006;27(4):229-232.

45. McCartan BE, Sullivan A. The association of menstrual cycle, pregnancy, and menopause with recurrent oral aphthous stomatitis: a review and critique. Obstet Gynecol. 1992;80(3 Pt 1):455-458. 